\title{
Los Wayúu, la Tierra y la POlítica del Carbón en la Guajira. 1980-2000: UnA Visión DESDE LA Historia PARA REPARAR Y NO REPETIR.*
}

\author{
Por: Judith Montero de Daza \\ Luis Mestra Narváez
}

\section{RESUMEN}

Los Wayúu se consideran a sí mismos "hijos de la tierra" y dueños únicos de todo cuanto existe sobre el suelo y el subsuelo guajiro. Para ellos, la suma de estos elementos hace parte de una especie de "poder absoluto" en donde el cementerio se constituye en un aspecto trascendental en el fortalecimiento de la identidad cultural. Con la explotación del carbón entre 1980 y 2000, se desconocieron dichos principios mediante la utilización de mecanismos neocolonialistas respaldados por el discurso de modernidad inevitable. De esta manera, el Cerrejón y los nativos iniciaron un proceso de negociación donde la Tierra fue el eje fundamental y a la vez punto de choque por su carácter ancestral o su valor como un bien comercial. Este proceso arrojó resultados heterogéneos para la Comunidad, debido a que en su gran mayoría las familias Wayúu no negociaron como un conjunto, sino que cada clan asumió su defensa y traslado a través de sus propios líderes. Pero otros en cambio, optaron por el uso de mecanismos legales disponibles en la ley colombiana para defender sus derechos, cobrando fuerza la militancia política a través de organizaciones como el Yanama.

\section{Palabras Claves: Wayłuu, modernidad, Cerrejón, negociación, Tierra.}

\section{ABSTRACS}

The Wayúu community consider to themselves "sons of the Earth" and owners of everything whatever exists on the ground and the subsoil guajiro. For them, the sum of these elements is part of a species of "absolute power" in where the cemetery is constituted in a transcendental aspect in the fortification of the cultural identity. With the operation of the coal between 1980 and 2000, these principles by means of the use of neocolonialistas mechanisms endorsed by the speech of inevitable modernity were not known. This way, the Hillock and the native ones initiated a negotiation 
process where the Earth was the fundamental axis and simultaneously point of shock by its ancestral character or its value like a commercial good. This process threw heterogenous results for the Community, because in their great majority the Wayúu families did not negotiate like a set, but that each clan assumed its defense and transfer through its own leaders. But others however, decided on the use of legal mechanisms available in the Colombian law to defend their rights, receiving forces the political militancy through organizations like the Yanama.

\section{Key Words: Wayuu, modernity, Cerrejón, negotiation, Hearth.}

\section{Presentación}

El presente artículo gira en torno a la etnicidad como elemento importante en el desarrollo de los procesos históricos del Caribe. En ese sentido, este trabajo se concentra en las particularidades de las relaciones que surgieron entre las Comunidades indígenas de la Media y Alta Guajira y la compañía carbonífera del Cerrejón, lo cual permitirá mostrar desde la Historia, los intermediarios y la evolución de los mecanismos de resistencia, adaptación y negociación adoptados frente a la incursión del complejo carbonífero en su "espacio y territorio étnico", punto crucial dentro del proceso durante los años 1980 - 2000. En el presente, la negociación y resistencia de los wayúu pasó de la confrontación directa y armada contra el "alijuna" -no Wayúu- a una lucha que dio vía a la asociación legal de clanes, la apropiación de instituciones y de un corpus legal brindados por el Estado para dirimir los conflictos, ambiente que se ha construido en "nuevas" formas de respuesta frente a las políticas del gobierno nacional y las empresas transnacionales. ${ }^{1}$

Desde el siglo XVI el proceso de poblamiento, "reducción" y "pacificación" de los indígenas en la Guajira, giró alrededor de la explotación de los naturales como los ostrales, ${ }^{2}$ el palo de tinte o "brasilete", ${ }^{3}$ la sal tradicionalmente controladas por la comunidad Wayuu y declarada monopolio estatal en $1884^{4}$ aunados a otros fenómenos como el contrabando y la ganadería durante el siglo XVIII y XIX. Para el siglo XX, la Guajira sería un punto clave dentro de la política energética mundial y en este sentido, el carbón se convertiría para la década del 70 en objetivo principal de grandes transnacionales como consecuencia de la crisis petrolera que mostró sus impactos en el mundo industrial de ese momento.

La referencia más antigua sobre la existencia del carbón en la Guajira parece estar en un informe de John May, contratado por el gobierno nacional para la exploración 
minera en la Guajira y quien reportó su descubrimiento en 1862, dando cuenta del hallazgo de este mineral situado "a orillas del río Cerrejón en el Distrito de Padilla" ${ }^{5}$ De allí resultarían muchos intentos por extraer el mineral ${ }^{6}$ pero sólo hasta 1979 se concretó un proyecto de explotación a través de la asociación conocida como Cerrejón Zona Norte S.A. conformada por Carbocol (Carbones de Colombia S.A. ) e Intercor (filial de la Exxon Móvil) por lo cual, amplias franjas territoriales de la península de la Guajira que comprenden espacios ancestrales y sagrados para los Wayúu, se convirtieran en objeto de negociaciones y conflictos entre las comunidades indígenas y la industria carbonífera, que necesitó cerca de 38.000 hectáreas - en la Media y Alta Guajira- para la infraestructura de la Mina, el Puerto de embarque, el ferrocarril, la carretera alterna al mismo y dos complejos habitacionales para sus empleados.

\section{El Conflicto por la Tierra}

Los Wayúu se consideran a sí mismos "hijos de la tierra" y dueños únicos de todo cuanto existe sobre el suelo, el subsuelo y todo cuanto sea producto de la misma naturaleza (el aire, las aguas, los animales, las plantas). La suma de estos elementos hace parte de una especie de principio de "poder absoluto" sobre todo aquello que existe y es usado o usufructuado diariamente. ${ }^{7}$ Dentro de este principio, el cementerio constituye un aspecto importante y trascendental. Cada individuo de un clan Wayúu aspira morir en su tierra, ${ }^{8}$ en el lugar donde habitaron sus mayores y antepasados, en el territorio clanil. ${ }^{9}$ Es así como el cementerio y los velorios sugieren una fuente de identidad étnica. ${ }^{10}$

Este aspecto se refleja claramente en la figura de las rancherías (píchipala), donde la relación entre parentesco y territorio se caracteriza por la presencia de asentamientos tradicionales que constan de un grupo de cinco a diez casas que componen el caserío. Una ranchería se inscribe dentro de una familia cuyo apellido se ha transmitido por matrifiliación, es decir, una agrupación humana que se ha conformado alrededor de la mujer más vieja, quien tiene

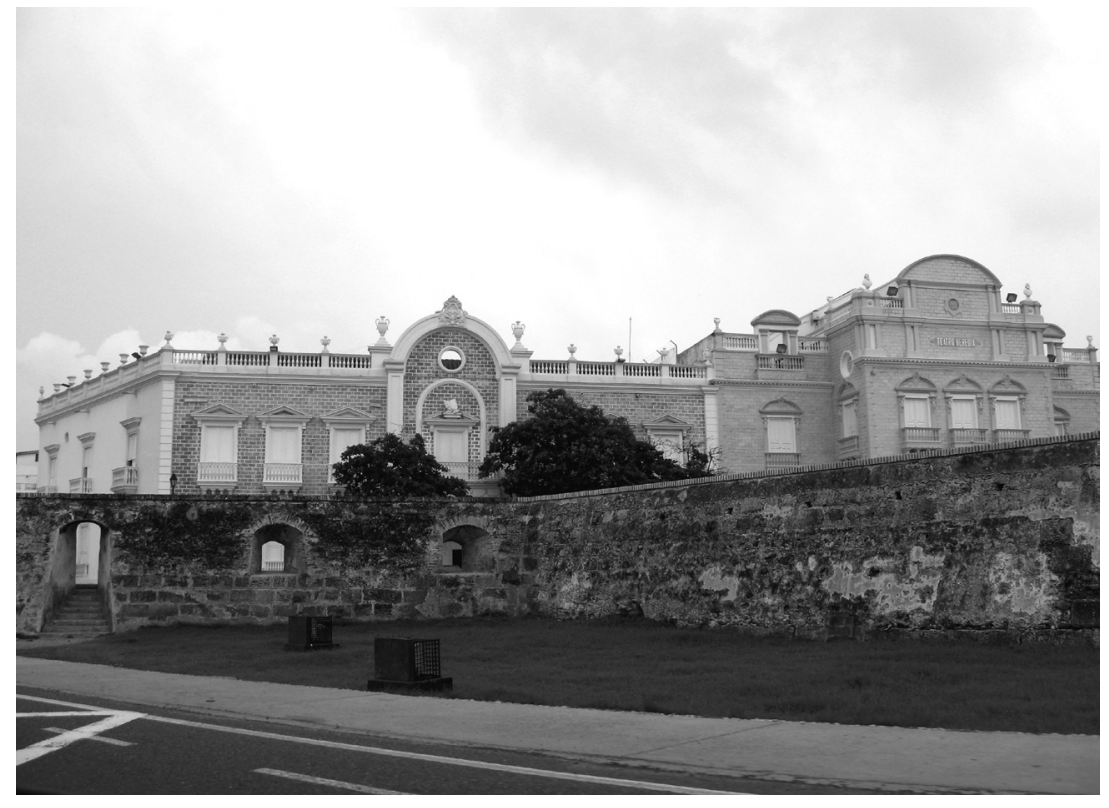


a las familias de sus hijos e hijas casadas, viviendo cerca de su propia casa o restos mortales. ${ }^{11}$ De esta manera, la Ranchería como conjunto de vivienda permanente, constituiría el asiento tradicional Wayúu por excelencia. ${ }^{12}$ Esta organización política y territorial de los Wayúu chocó frontalmente contra los planes del Cerrejón, debido a que la misma distribución de las rancherías durante las negociaciones hizo que el proceso fuera discontinuo y asumiera tintes particulares a medida que avanzaba la construcción de la vía férrea y el puerto.

En las negociaciones, la Tierra fue el eje fundamental y a la vez punto de choque de sentidos en torno a su carácter ancestral o su valor como un bien comercial. Al llegar la Compañía a la Guajira y comenzar la construcción de carreteras, vías férreas y demás, el panorama de la región cambió. Para los técnicos, ingenieros y administradores del Cerrejón, no había apushis ni sitios sagrados. En sus mapas sólo aparecían canteras, campamentos, torres de comunicación, puentes y muchos otros datos necesarios para el proyecto. Los cerros y otros lugares sagrados se convirtieron en kilómetros y edificaciones del Cerrejón. ${ }^{13}$

Por otro lado para los Wayúu, la tierra no se considera un bien comercial que requiera ser cuantificada para valorarla, es simplemente un bien de uso y su única limitación es la que esté siendo utilizada por otro. Esta construcción cultural descansa sobre valores consuetudinarios (plasmadas en la costumbre) aceptados y practicados por todos sus miembros, y transmitidos de generación en generación. ${ }^{14}$ En este sentido, el Cementerio representa la materialización de sus escrituras sagradas, cuyo valor es equiparable o superior al valor de un documento que los acredite como verdaderos dueños de un amplio territorio. Esta lógica que muy poco entendió el Imperio español en el pasado, en el presente sigue siendo un elemento de choque con los "alijunas". Por esa razón durante el proceso de negociación de las tierras del Cerrejón Zona Norte, la cuestión del traslado de los cementerios se convirtió en un punto crucial para la aceptación del desplazamiento formal por parte de los Wayúu. ${ }^{15}$

Con el montaje del complejo minero del Cerrejón, este derecho de propiedad empezó a verse amenazado debido a que en 1981 el Estado, a través del Incora legitimó el ingreso de la Compañía y otras entidades estatales mediante la creación de reservas y resguardos en la Alta y Media Guajira. ${ }^{16}$ En ese momento la decisión se fundamentó sobre un discurso estatal que catalogaba estos terrenos como "baldíos". ${ }^{17}$ El resguardo que en el pasado se convirtió en una iniciativa de la Corona española para concentrar a los indígenas en poblados 
e insertarlos eficazmente al sistema colonial. ${ }^{18}$ fue asumida nuevamente en el siglo XX - mediante la ley 135 de 1961- por el gobierno colombiano para justificar el desplazamiento de los indígenas de zonas que representaban algún tipo de interés económico o político en el país.

Por otro lado, la figura de las Reservas es otro mecanismo legal del presente, que permite al Estado la expropiación de terrenos estratégicos considerados como "baldíos" cuyas riquezas del suelo y el subsuelo es potencialmente explotable a título propio o a través de un concesionario. ${ }^{19}$ Este criterio permitió que en la Guajira muchos territorios indígenas fueran clasificados de esta forma debido a que muy pocos Wayúu conservaron documentos físicos para demostrar ante la ley nacional su posesión. Estas figuras dejaban de lado las creencias y el valor que estos territorios tenían para nativos mediante el supuesto de que nadie las habitaba y mucho menos que pertenecían a comunidad alguna. ${ }^{20}$ Con este rótulo, la presencia Wayúu en las tierras de la concesión minera fue invisibilizada.

Al ignorar los mecanismos tradicionales de apropiación de la tierra se desconoció su cultura. Este hecho despertó la indignación de los indígenas e hizo prioritario obtener la titulación de sus propiedades, para evitar los abusos de los terratenientes en la Alta y Media Guajira y también del Cerrejón. ${ }^{21}$ fenómeno que evidentemente constituía en sí mismo, un cambio agresivo que transgredía la forma cultural sobre territorialidad entre los Wayúu. ${ }^{22}$ Al respecto, ellos manifestaron lo siguiente:

O sea lo que en la época de la Colonia, lo que el rey de España no pudo con todo su ejército controlar el territorio wayúu, nosotros lo perdimos entre el 78 y 82. Mejor dicho, se quebró todo lo que es el territorio wayúu: nos lo partieron por la mitad (a propósito de la construcción de la carretera mina-puerto y la vía férrea) ${ }^{23}$

Otra consecuencia que generó el desconocimiento de la ley tradicional Wayúu sobre el derecho al uso de la tierra fue la búsqueda y adopción de mecanismos legales disponibles en la ley colombiana para defender sus derechos. En este sentido, cobró fuerza la militancia política a través de organizaciones como el Yanama y la apropiación del discurso jurídico alrededor de la tierra que le ofrecía la Constitución Nacional. A propósito Joanne Rappaport menciona que el uso de documentos e instituciones legales por parte de los indígenas, no puede interpretarse como una simple subordinación a las disposiciones del Estado debido a que en casos como el de los Wayúu, el apropiarse de la palabra 
escrita y enriquecerlas con la tradición oral, se convierte en un complemento de su lucha por la defensa de su cultura, que lejos de desarticular su forma tradicional de negociación, les permite hablar en "igualdad" de condiciones y en los mismos términos jurídicos con los organismos estatales y multinacionales extranjeros. ${ }^{24}$

\section{La Negociación Política con los Clanes Indígenas}

El trazado del proyecto de instalación del Cerrejón requería la desocupación de una amplia zona habitada en su gran mayoría por familias del clan Epinayú, "Este hecho representaba una razón obligada por la cual los grupos afectados debían trasladar sus ranchos, rebaños, jagüeyes y cementerios". ${ }^{25}$ Por este motivo, se hacía necesario el comienzo de una etapa de negociación con los líderes de cada una de las familias ubicadas dentro de este corredor vial. Para desempeñar esta tarea, la junta administrativa del Cerrejón delegó a un grupo de profesionales la tarea de "persuadir" a los indígenas para que pacíficamente aceptaran su traslado a zonas aledañas a la Reserva Nacional. ${ }^{26}$

Entre los comisionados para esta labor figuraba el asesor Alberto Girado Caballero, a quien la comunidad Wayúu en 1996 declaró "Hijo de la Luna". Este título además de indicar que a partir de ese momento se convertiría en un miembro más de los wayúu, ${ }^{27}$ era la materialización de una estrategia política emprendida por la Compañía carbonífera la cual buscó desde el principio ganar la confianza de los nativos instalados en la zona de Reserva. Como antecedente histórico, en los siglos XVIII y XIX la corona española delegó dicha labor a las Misiones Capuchinas quienes emprendieron las tareas de "persuasión, pacificación, reducción y congregación de los indios" en pueblos recién fundados. ${ }^{28}$

Al contar el Cerrejón con el aval del gobierno tenía la tarea adicional de conseguir el consentimiento de sus dueños directos en la Guajira: los Wayúu. Esta etapa requirió de un equipo de personas capaces de "vender" muy bien el proyecto a los nativos de tal forma que su actitud ante el desalojo se diera de la mejor manera posible. ${ }^{29}$ Para la Exxon y su filial Intercor la labor de funcionarios como Girado era fundamental en el logro de esta meta. El día en que éste recibió el título Wayúu se dieron cuenta de que habían cumplido con sus objetivos al enviarle no un trabajador de la compañía, sino una especie de misionero que entendió desde el principio las necesidades de los indígenas y con respecto al nombramiento, la revista internacional Lámpara de la Exxon en Estados Unidos publicó lo siguiente: 
Por 15 años Girado ha sido un misionero moderno enviado por la empresa industrial más grande en Colombia para cuidar de los indígenas de la Guajira. Recientemente, en una ceremonia sagrada, los Wayúu lo bautizaron....y lo hicieron Cacique, jefe de líderes [...y] Vestido como un Cacique, Girado dijo a los Wayúu: "Yo estaré con ustedes siempre, caminaré por sus caminos, me mojaré con su lluvia y viviré bajo la misma luz que ustedes lo han hecho". ${ }^{30}$

En cuanto a la forma en que negociaron las familias, el señor Edgar Sarmiento, actual jefe de la División de Tierras del Cerrejón, afirma en su versión de los hechos, que un elemento predominante en las negociaciones fue la costumbre Wayúu: "Ellos negociaron con bloques que tienen de familias muy asociadas a rancherías vecinas [...] allí tienen su palabrero o su líder familiar que asesora al palabrero". ${ }^{31}$ Según Sarmiento, no era extraño, que varios tramos de parcelas pertenecientes a un área en común fueran negociados por una misma persona, cuyos beneficios se traducían de manera diferente para las familias por él representadas. Y agrega:

Que la persona en este caso podía hacer de intermediario, de palabrero negociador a los parientes cercanos de esa área e inmediatamente llegaba a un límite donde ellos lo reconocían claramente y entraba otra casta [...] y allí ya no negociaban ellos, ya negociaban los del otro lado y allí seguían negociando otras castas y así hasta llegar hasta Puerto Bolívar. Pero no había solo uno o dos líderes para negociar los $150 \mathrm{~km}$ [...] eso fue muy al estilo wayúu con representantes locales en cada área donde se iban identificando, digamos las tenencias sobre la tierra. ${ }^{32}$

Lo anterior es evidencia de que los Wayúu en su gran mayoría no negociaron con la empresa como un conjunto, sino que desde un principio cada población expuso - a través de su propio intermediario- sus intereses. Los resultados obtenidos mediante este proceso fueron heterogéneos debido a la propia distribución del territorio ancestral que poseían estas comunidades. ${ }^{33}$ Mientras que en otros casos los nativos no aceptaron la propuesta como en Media Luna cercano a Puerto Bolívar, donde los Wayúu decidieron no emigrar pese a las consecuencias que pudiesen traer a nivel del aire y su cercanía con el punto de embarque del Cerrejón. ${ }^{34}$ Dentro de la lógica de la cultura wayúu, la negativa a trasladarse más allá de Media Luna obedecía al profundo respeto que inspiraba el derecho tradicional de la tierra que tenían los clanes que ya ocupaban esas zonas y en este sentido Remedios Fajardo explica lo siguiente:

La familia Wayúu de Media Luna no entregó sus tierras por dinero ya que el problema

Palobrano. 9 Agosto/2008 
no consistía en vender a buen precio o lograr mayores beneficios. La verdad es que la familia Uriana y Epinayú que se quedaron allí no tenían para dónde irse. Todos los territorios cercanos estaban ocupados mucho más allá de lo que por tradición han estado. Si ellos salen de sus tierras, el resto de vecinos no les permitirá asentarse en sus territorios, les preguntarán ipor qué entregaron las tierras que Juya (la lluvia) les dio? ¿Qué vienen a buscar ahora en nuestras tierras? Según la tradición del pueblo wayúu quien cede sus tierras para quedarse sin ellas, pierde status ante la comunidad, y pierde credibilidad para asumir responsabilidades comunitarias. ${ }^{35}$

Girado Caballero afirma que hubo otros casos en los que algunos líderes Wayúu reaccionaron de manera "belicosa" frente a su propuesta. La explosión de furia estaba demostrando la sensibilidad que este tema producía en los nativos ante la pérdida de su territorio ancestral. ${ }^{36}$

\section{El Traslado de Poblados}

Este fenómeno en la Guajira tiene sus antecedentes en el período Colonial. En el siglo XVIII este mecanismo se convirtió en una estrategia frecuente emprendida por la Corona española para reducir y controlar el territorio de los nativos. En su primera etapa, se requirió del apoyo de misioneros Capuchinos para empezar un proceso de reducción y creación de poblados sobre una comunidad que desde el principio se mostró reacia a dejar sus tierras y articularse al sistema colonial como "vasallos del rey". ${ }^{37}$ Si en la Colonia el objetivo de los religiosos era la reducción y pacificación de los indígenas, en el presente los negociadores de la Compañía buscaban desplazarlos y reducir su radio de acción al enviarlos a zonas de Resguardo que la nación había destinado para ellos. ${ }^{38}$ Las misiones en el siglo XVIII intentaron quebrar el eje central de la cultura Wayúu: el principio de reciprocidad y la estructura del apüshi como forma de asentamiento; en el siglo XX, el propósito era más directo, el Cerrejón necesitaba las tierras y ellos eran un impedimento para obtenerlas.

Algunos funcionarios como Alberto Girado Caballero y Edgar Sarmiento, reconocen que los efectos de un proceso de esta magnitud ocasionaron en los indígenas problemas que trascendieron al plano psicológico. Ambos aseguraban que la reubicación de una población se convertía en una tarea indeseable y compleja para el Cerrejón, debido al impacto cultural que esto tenía en las poblaciones y los elementos socioeconómicos que entraban en la negociación; en ese sentido, Sarmiento sostenía lo siguiente:

Con todo lo que se haga, los reasentamientos de caseríos es la última opción a la que 
recurre un proyecto para avanzar [...] después de analizar todo lo que pudiera ser [...] es que uno dice, no hay otro [...] eso es indeseable para cualquier empresa en cualquier proyecto, en cualquier situación es indeseable reasentar poblaciones [...] y no es indeseable por el dinero, lo que lo hace más indeseable es el factor cultural [...] porque hay cosas que culturalmente jamás, en ningún asentamiento se pueden compensar [...] el paisaje, la bonga de al lado del río, el cementerio viejo, el palo de mamón de mi abuelo [...] esas cosas jamás se podrán compensar [...] y eso siempre deja heridas sobre todo en la generación de los adultos mayores, que muchos no se recuperan y algunos viejos les queda una tristeza del proceso y mueren con ella, pero los más jóvenes se cambian el "disco" y entran que no hay mal que por bien no venga y entran por la nueva oportunidad de irse para otro lugar [...] por la oportunidad económica [...] ellos tienen sus propias aspiraciones. ${ }^{39}$

La Militancia Étnica Frente al "Indigenismo alijuna"

En la Guajira, las estrategias de "acompañamiento" a las comunidades Wayúu están en manos de la Oficina de Asuntos Indígenas y la Casa del Indígena. Pero frente al Cerrejón, presentaron falencias que fortalecieron la "visión de normalidad" del proceso a favor de la compañía, debido a que los documentos que respaldaban las quejas que los nativos habían presentado se habían deteriorado por estar a la intemperie y las únicas copias existentes se encontraban archivados en la entidad demandada, la cual se reserva el derecho de admisión.

Ante estas deficiencias los Wayúu se vieron en la necesidad de organizarse políticamente para defender su cultura y sus territorios de la usurpación de entes nacionales y extranjeros. Ejemplo de ello es la organización indígena Yanama, ${ }^{40}$ la cual se constituye como la primera Organización Indígena de la Guajira que auxiliada por profesionales nativos o ajenos a la comunidad, buscan estudiar y comprender la cultura Wayúu frente a los cambios que pueda producir el contacto estrecho con la "cultura nacional". ${ }^{41}$ Es por ello que ante el Cerrejón, esta organización siempre estuvo a la expectativa de los resultados que trajera consigo el proceso de negociación.

Para ellos el tema de la explotación del carbón del Cerrejón no tenía un interés trascendental hasta el momento en que el funcionamiento del complejo puso en peligro su integridad cultural. En respuesta a ello, en noviembre de 1983 la Organización Indígena envió una carta al Gerente general del Incora, Ernesto Muñoz Orozco, afirmando lo siguiente: 
Durante cientos de años nuestras tierras ancestrales se salvaron de la invasión y devastación que los alijunas causaron en otras partes de América. Por más de 300 años de régimen colonial, resistimos todo esfuerzo por arrebatarnos nuestra tierra y reducir nuestro pueblo. Durante el siglo pasado, el gobierno republicano nos dejó en paz sin interferir en nuestras tierras ni afectar nuestras vidas. Esta situación comenzó a cambiar en el presente siglo cuando los alijunas, a través del comercio y otras actividades propias de ellos, fueron penetrando la tierra de nuestros abuelos.

El año pasado las cosas tomaron un rumbo inesperado e inaceptable para nuestro pueblo. Los alijunas dispusieron inconsulta e inapelablemente que muchos de nuestros hermanos vendieran sus viviendas, corrales y huertas y sacaran los huesos de sus abuelos para darle paso a una carretera, un ferrocarril y un puerto carbonífero. Este proyecto poco nos beneficia y en cambio sí daña nuestra tierra. Los alijunas pueden comer de El Cerrejón, pero ni nosotros ni nuestro rebaño podemos vivir de él.

Nuestra tierra ancestral en la que nacieron, vivieron y murieron nuestros abuelos, donde criaron sus ganados y cosecharon sus huertas para luego reposar al lado de sus abuelos, como lo hemos hecho desde tiempo inmemorial, esa tierra dura y agreste y hermosa nos dicen hoy los alijunas que no tienen dueño, que es un baldío. No podemos callarnos "wopümain, jaláala y wimpümüin" comienzan a ser desmembrados como una res que mata y regala el gobierno a sus amigos. Muchos alijunas reclaman reservas de nuestro territorio para traer turistas, explotar este o aquel recurso que nos pertenece a nosotros los Wayúu.

Por cientos de años, hemos vivido cuidando nuestros pozos, nuestras huertas y nuestros

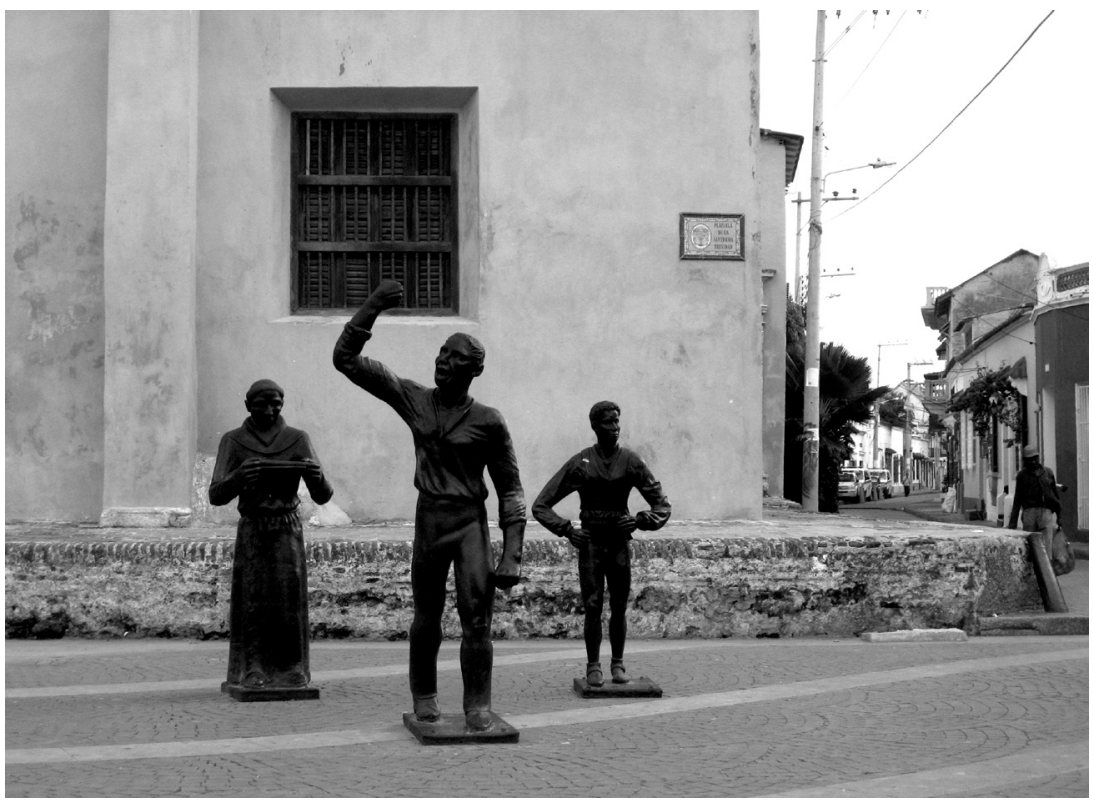
rebaños en esta tierra. Hoy, que sin consultarnos los alijunas comienzan a despedazar nuestro territorio, no podemos quedarnos callados $y$ dejar que eso suceda sin que nosotros movamos un dedo para protegernos.

Esta carta sintetiza con mucha claridad la percepción que tenían los nativos "políticamente organizados" sobre la instalación del complejo minero en la península $y$ las transformaciones que esto traería consigo. Otro ejemplo de 
su actuación ocurrió en 1989 cuando se pronunciaron frente a un nuevo macroproyecto vial en la Guajira donde reclamaban que la carretera Mina-Puerto y la vía férrea del complejo minero ya se convertían en antecedentes nefastos para los Wayúu porque en vez de beneficiarlos lograron en su lugar, desarticular aún más su territorio ancestral. ${ }^{42}$

Por otro lado, la compañía como "un nuevo agente de cambio" en la Guajira, produjo en algunos la sensación de que en el siglo XXI la región volvía a ser un espacio potencial de colonización; pero en este caso, no bajo la égida de la religión católica, sino bajo un discurso de progreso y modernidad inevitables. ${ }^{43}$ La cuestión era que para lograr tal fin se necesitaba que todos los guajiros hicieran parte de ello y esto incluía nuevamente a los Wayúu, quienes al igual que en la Colonia, se convirtieron en un "freno" para las políticas estatales y transnacionales; razón por la cual, debían ser otra vez enfrentados y reubicados para conveniencia de estos últimos.

El discurso de progreso del Cerrejón, se fortaleció con la intervención de mediadores locales y nacionales que obviaron lo negativo del mismo y defendieron los resultados positivos de la instalación del Complejo en la región. Era claro que el objetivo de los asesores del Cerrejón en las negociaciones por las tierras, iba encaminado a crear un ambiente de "tranquilidad" y "confianza" con los Wayúu mediante la realización de obras que "beneficiarían" a la comunidad y demostraran que la Compañía antes que perjuicios pretendía mejorar sus problemáticas. ${ }^{44} \mathrm{~A}$ pesar de todo este despliegue "persuasivo" para algunos, estos actos lejos de ser muestras altruistas, sólo buscaban prolongar una imagen internacional de buen manejo debido a que dichos aportes a la comunidad, tan difundidos a través de vallas publicitarias y otros medios de comunicación, pretendían dar cuenta del estrecho compromiso de la Mina con la población indígena pero que según Jonathan Echeverri, a la Compañía en realidad, no le interesaba estrechar ningún tipo de lazos con los wayúu. ${ }^{45}$

Al ver la planta física del Cerrejón y la forma como opera diariamente, queda una imagen de grandes proporciones que impacta necesariamente hasta al más desprevenido. No obstante, detrás de todo ello está la realidad de un pueblo que debió dejar sus tierras para que eso fuera realidad y son ellos quienes a su manera han intentado entender dentro de su propia lógica lo que el Cerrejón les ha vendido como progreso.

Lo que no sabíamos era, que lo que ellos llamaban progreso iba a ser la destrucción

Palobrano. 9 Agosto/2008 
de nuestros pueblos. Intercor, filial de la Exxon-Mobil, fue la empresa encargada en hacer las exploraciones, en hacer la explotación del carbón. Y cuando llegaron eran amables con la gente, hacían reuniones e invitaban a los jefes de familia, miraban quiénes eran los líderes de las comunidades y los iban amansando. ${ }^{46}$

Como muestra de la percepción de los Wayúu frente al "progreso", Girado explica que en una ocasión un indígena Wayúu llamado "Lucho" muy molesto lo fue a buscar a la Compañía para exigirle el pago del vidrio delantero de su carro. Lo particular de su reclamo era la forma cómo argumentó el hecho de que el Cerrejón era el directo responsable de este desafortunado incidente

Pues al cruzarse con otro vehículo en la carretera, saltó una piedra y se lo rompió... [Girado tratando de hacerlo razonar le preguntó] ¿Qué culpa tenemos nosotros de lo sucedido? [A lo que Lucho respondió] - Kasukish, tu sabes que yo compré este carro con el dinero que me distes de las mejoras. Si ustedes no hubieran venido por aquí yo no compro nunca un carro y al no tener carro, no se me hubiera roto el vidrio. ${ }^{47}$

El funcionario lo entendió cómo la manifestación de una cadena de dependencia generada por el Complejo en la región y suponía que esto debía ser cortado de alguna forma; pero por otro lado, la reacción de "Lucho" encubría el hecho de que no todo había sido beneficios para los Wayúu y que toda transformación en su cotidianidad era el producto de la explotación del carbón y de los mecánicos implementados por sus asesores para lograr el desalojo de las tierras. De esta manera "Lucho" reafirmaba una gran conclusión de todo este proceso que indicaba que tan mencionada modernización en la Guajira había llegado sólo para alterar un orden espacial y cultural difícilmente subsanado con una simple indemnización monetaria.

\section{BIBLIOGRAFIA}

AUTORES VARIOS. (1986). Guajira: aspectos geográficos, Ministerio de Hacienda y Crédito Público, Instituto Geográfico Agustín Codazzi - IGAC, Bogotá.

ARDILA, Gerardo (Ed.) (1990), La Guajira: de la memoria al porvenir. Una visión antropológica, Universidad Nacional de Colombia. Bogotá.

ARIZA, Hilario. (1980). 100 años del Cerrejón, El Espectador, septiembre 21, pág. 13 A, Bogotá.

BARRERAMONROY, Eduardo. (2000), Mestizaje, comercio y resistencia. La Guajira 
durante la segunda mitad del siglo XVIII, Instituto Colombiano de Antropología e Historia-ICANH-, Bogotá.

DE LA PEDRAJA, René. (1981) La Guajira en el siglo XIX: Indígenas, contrabando y carbón, Tomado de Desarrollo y Sociedad, Centro de Estudios de Desarrollo Económico-CEDE, Universidad de los Andes, Pág. 1 - 38, Bogotá.

ECHEVERRI, Jonathan. (2003). El contacto y la configuración de la identidad wayúu: un recuento de interacciones pasadas y presentes. En: Boletín de Antropología, Universidad de Antioquia, vol. 17, No 34, págs. 80 - 92. Medellín.

FAJARDO GÓMEZ, Remedios. (2007), Violación sistemática de los derechos humanos, En: Chomsky, Aviva. Garry Leech y Steve Striffler. Bajo el manto del carbón. Pueblos y multinacionales en las minas de El Cerrejón, Colombia, Casa Editorial Pisando Callos, Págs. 17 - 30. Bogotá.

FORERO NOUGES, Mike. (1983). Informe de la Guajira (6). El indígena no es el invasor, El Espectador, mayo 6, pág. 9A. Bogotá.

. (1983). Informe sobre la Guajira (3). Un ferrocarril llamado deseo, El Espectador, mayo 3, pág. 4A, Bogotá.

GIRADO CABALLERO, Alberto. (1998), "Nu shon kashi", Hijo de la Luna. Talleres Sáenz Impresores del Caribe, Barranquilla.

GONZÁLEZ VERGARA, Otto. (1990). "Los wayúu. Hombres del desierto", En: Ardila, Gerardo (Comp.), La Guajira. De la memoria al porvenir una visión antropológica, Universidad Nacional de Colombia, págs. 145 y 155. Bogotá.

GUTIÉRREZ, Josefa. (1996). El hijo de la Luna, en la tierra wayúu, El Heraldo, domingo 3 de marzo, pág. 1C. Barranquilla.

HERRERA ÁNGEL, Marta. (2002). Ordenar para controlar. Ordenamiento espacial y control político en las llanuras del Caribe y en los Andes centrales Neogranadinos. Siglo XVIII, Academia Colombiana de la Historia, Instituto Colombiano de Antropología e Historia, Bogotá.

HERRERA ÁNGEL, Marta. (2002), El Arrochelamiento: Nominar para criminalizar, El Taller de la Historia ( $\mathrm{N}^{\circ}$ 2), Universidad de Cartagena, Facultad de Ciencias

Palobrano. 9 Agosto/2008 
Humanas. págs. $11-46$, Cartagena.

MARTÍnEZ GARNICA, Armando. Rueda Cardozo, Juan. (1996). La Provincia de los Mares. Orígenes de sus poblamientos urbanos, Ediciones UIS, Bucaramanga.

NIVIA MÉNDEZ, Luz Marina y Astrid Patricia RODRÍGUEZ. (1985), Impacto socio-cultural del proyecto Cerrejón en el Grupo Epinayú, Trabajo de Grado presentado como requisito para optar al título de Licenciadas en Ciencias Sociales, Universidad de la Sabana, Facultad de Ciencias Sociales, Bogotá.

PINEDA, Roberto. (1963). "El indio guajiro", En: Gühl, Ernesto (compilador), Indios y blancos en la Guajira, ediciones tercer Mundo. Págs. 81 y 99. Bogotá.

POLO ACUÑA, José. (2000). En defensa de la tierra: Poblamiento y conflicto social en la frontera guajira (siglo XVIII), En: Suárez, Normando (editor). La Guajira: pluriétnica y multicultural, Fondo Mixto para la Promoción de la CulturaGobernación de la Guajira, Imprenta Nacional de Colombia, Riohacha.

POLO ACUÑA, José, (2000). Contrabando y pacificación en una frontera del Caribe colombiano: La Guajira (1750-1800), Aguaita, 3, Observatorio del Caribe, junio, pág. 41 - 62. Cartagena.

POLO ACUÑ̃A, José. (2005). Etnicidad, conflicto social y cultura fronteriza en la Guajira (1700 - 1850), Uniandes, Ministerio de Cultura, Bogotá.

RAPPAPORT, Joanne. (2005). Cumbe renaciente una historia etnográfica andina, Instituto Colombiano de Antropología e Historia, Bogotá.

RIVERA, Alberto. (1990). "El desarrollo como una manera de construir la realidad", En: Ardila, Gerardo. La Guajira: de la memoria al porvenir. Una visión antropológica, Universidad Nacional de Colombia, Bogotá.

SALAS BAHAMÓN, Jaime Ernesto. (2004). "El Cerrejón y sus efectos: una perspectiva socioeconómica y ambiental", junio de 2004, disponible en: www. lablaa.org/blaavirtual/tesis/colfuturo/elcerrejonysusefectos.pdf, Bogotá.

SOLANO SARDOT, Ensito. (1990). Carbogringocol, En: Antena informativa, junio - julio, Pág.2l, Maicao. 
STEINER, Claudia. (2000). Imaginación y poder. El encuentro del interior con la Costa en Urabá, 1900 - 1960, Editorial Universidad de Antioquia, Colección Clío, Medellín.

VIZCAÍNO, Edén. Sociología del derecho y la cultura wayúu, Editorial Antillas, Barranquilla.

Entrevista a Edgar SARMIENTO, jefe de la División de Tierras del Cerrejón, 29 de junio de 2006, casete No 02. Cerrejón Zona Norte.

BIOGRAFIA

\section{JUDITH MONTERO DE DAZA}

Historiadora - Facultad de Ciencias Humanas de la Universidad de Cartagena. Miembro del grupo de investigación Frontera, sociedad y región en la Costa Atlántica, Siglos XVIII - XIX de la Universidad de Cartagena.

E-mail: jumoncan@hotmail.com

\section{LUIS EDUARDO MESTRA NARVAEZ}

Historiador - Facultad de Ciencias Humanas de la Universidad de Cartagena. E-mail: luismest2001@hotmail.com

\section{NOTAS AL PIE}

* Articulo basado en el trabajo de grado para optar el titulo de historiadores en la Facultad de Ciencias Humanas de la Universidad de Cartagena "Comunidades indígenas y carbón en la Guajira. 1980 - 2000. Una visión desde la Historia."

1 Véase el caso de los indígenas de la Comunidad Cumbal en Nariño, presentado por: Rappaport, Joanne (2005). Cumbe renaciente una historia etnográfica andina, Bogotá, Instituto Colombiano de Antropología e Historia, págs. 156 - 159; Ver: Martínez Garnica, Armando. Rueda Cardozo, Juan (1996). La Provincia de los Mares. Orígenes de sus poblamientos urbanos, Bucaramanga, Ediciones UIS, 1996, págs. 41 - 42 y 51 - 53

2 Polo Acuña, José. (2000). "En defensa de la tierra: Poblamiento y conflicto social en la frontera guajira (siglo XVIII)”, En: Suárez, Normando (editor). La Guajira: pluriétnica y multicultural, Fondo Mixto para la Promoción de la Cultura-Gobernación de la Guajira, Imprenta Nacional de Colombia, , pág. 109. Riohacha.

3 De la Pedraja, René. (1981). "La Guajira en el siglo XIX: Indígenas, contrabando y carbón", 
Tomado de Desarrollo y Sociedad, Bogotá, Centro de Estudios de Desarrollo Económico-CEDE, Universidad de los Andes, Pag. 6. El palo de brasil fue cortado especialmente por los naturales para los holandeses en Bahía Honda, el Portete, Mochila y en las inmediaciones del Valle de Upar y Buritaca (Sierra Nevada de Santa Marta). Ver: Barrera Monroy, Eduardo.(2000) Mestizaje, comercio y resistencia. La Guajira durante la segunda mitad del siglo XVIII, Instituto Colombiano de Antropología e Historia-ICANH-, pág. 110. Bogotá.

4 Autores Varios.(1986). Guajira: aspectos geográficos, Ministerio de Hacienda y Crédito Público, Instituto Geográfico Agustín Codazzi - IGAC, , pág. 72. Bogotá.

5 De la Pedraja, René.(1981). Op. Cit, págs. 31 y 32.

6 Ariza, Hilario. (1980). "100 años del Cerrejón”, El Espectador, septiembre 21, pág. 13 A. Bogotá.

7 Vizcaíno, Edén. Sociología del derecho y la cultura wayúu, Editorial Antillas, págs., 114 y 115. Barranquilla.

8 Ver el caso de la población de los indios perleros que negoció el capitán Pacho Agámez, en el siglo XVIII y el traslado de los restos mortales de Bernardino Peñaranda hacia la zona de Bahía Honda por su sobrino materno "para enterrarlos allí por ser de aquel paraje". Polo Acuña, José. (2000). Op. Cit. págs. 117 y 126

9 Pineda, Roberto. (1963). "El indio guajiro", En: Gühl, Ernesto (compilador), Indios y blancos en la Guajira, Bogotá, ediciones tercer Mundo, P. 81 y 99. Ver: Polo Acuña, José. (2005). Etnicidad, conflicto social y cultura fronteriza en la Guajira (1700 - 1850), Uniandes, Ministerio de Cultura. págs. 64 - 67. Bogotá.

10 Barrera Monroy, Eduardo. (2000). Op. Cit., pág. 63

11 González Vergara, Otto. (1990). "Los wayúu. Hombres del desierto", En: Ardila, Gerardo (Comp.), La Guajira. De la memoria al porvenir una visión antropológica, Universidad Nacional de Colombia, págs. 145 y 155. Bogotá.

12 Autores Varios. (1986). Op. Cit., pág. 147

13 Rivera, Alberto. (1990). "El desarrollo como una manera de construir la realidad", En: Ardila, Gerardo. La Guajira: de la memoria al porvenir. Una visión antropológica, Universidad Nacional de Colombia, Pag. 244. Bogotá.

14 Autores Varios. (1986). Op. Cit., pág. 77.

15 Vizcaíno, Edén., Op. Cit. pág. 114, 115 y 116. Durante el siglo XVIII, el proceso de "pacificación" de los "indios goajiros" y el traslado de cementerios se convirtieron en una de las empresas más arduas llevadas a cabo por la Corona española. Un ejemplo de ello fueron las comunidades que habitaron zonas de la Macuira y Chimare, que ante la presencia de los españoles, defendieron con armas sus territorios, sus cementerios y los recursos naturales allí presentes. En todo este proceso las misiones capuchinas jugarían un papel importante para la obtención de dicho objetivo. Ver: Polo Acuña, José, (2000). "Contrabando y pacificación en una frontera del Caribe colombiano: La Guajira (1750-1800)”, Aguaita, 3, Cartagena, Observatorio del Caribe. pág. 41 - 62.

16 Forero Nougués, Mike. (1983). "Informe de la Guajira (6). El indígena no es el invasor", El Espectador, pág. 9A. Bogotá.

17 El Baldío es una figura jurídica y política que construye un espacio vacío e ignora la existencia de pobladores nativos. Ver: Martínez Garnica, op. cit, págs. 51 - 53

18 Herrera Ángel, Marta. (2002). Ordenar para controlar. Ordenamiento espacial y control político en las llanuras del Caribe y en los Andes centrales Neogranadinos. Siglo XVIII, Academia 
Colombiana de la Historia, Instituto Colombiano de Antropología e Historia, pág. 126. Bogotá.

19 Martínez Garnica. Op. Cit., pag. 41.; Autores Varios. (1986). Op. Cit., Págs. 79, 140 y 146.

20 Este tema ocupa un lugar considerable en la historia nacional y se ha demostrado que tras la declaratoria de numerosos territorios como zonas de "indios bélicos", "arrochelados" o en su defecto "territorios baldíos", siempre han existido otros intereses adicionales por parte de Estado. Ver: Martínez Garnica. Ibíd. (1996) págs. 51 - 53, 75, 69 y 95; Herrera Ángel, Marta. (2002). "El Arrochelamiento: Nominar para criminalizar", El Taller de la Historia, 2, Universidad de Cartagena, Facultad de Ciencias Humanas, Págs. 41 y 42.

21 Nivia Méndez, Luz Marina y Astrid Patricia Rodríguez Silva. (1985) Impacto socio-cultural del proyecto Cerrejón en el Grupo Epinayú, Trabajo de Grado presentado como requisito para optar al título de Licenciadas en Ciencias Sociales, Universidad de la Sabana, Facultad de Ciencias Sociales, pág. 192. Bogotá.

22 Ibíd., pág. 192

23 Echeverri, Jonathan. (2003), "El contacto y la configuración de la identidad wayúu: un recuento de interacciones pasadas y presentes", Boletín de Antropología, vol. 17, No 34, Universidad de Antioquia, pág. 87. Medellín.

24 Rappaport, Joanne. (2005). Op. Cit. Págs. 166 y 167

25 Girado Caballero, Alberto. (1998). "Nu shon kashi", Hijo de la Luna. Barranquilla, Talleres Sáenz Impresores del Caribe, pág. 20.

26 Forero Nougués, Mike. (1983) "Informe de la Guajira (6). El indígena no es el invasor", El Espectador, pág. 9ª Bogotá.

27 Gutiérrez, Josefa. (1996). "El hijo de la Luna, en la tierra wayúu”, El Heraldo, domingo, pág. 1 C. Barranquilla.

28 Polo Acuña, José, (2000) Op. Cit., pág. 55. Aguaita.

29 En la región de Urabá, luego de ser anexada al departamento de Antioquia se inició una lucha por cambiar desde la escuela los referentes históricos de los niños para que comprendieran que Antioquia no explotaba esas regiones "para llevar su productos y convertirlos en frivolidades y lujo en Cartagena y en el extranjero", sino que los hijos del departamento trabajaban allí para beneficiar a la misma región mejorando su comercio y su organización. Ver: Steiner, Claudia. (2000) Imaginación y poder. El encuentro del interior con la Costa en Urabá, 1900 - 1960, Editorial Universidad de Antioquia, Colección Clío, pág. 67. Medellín.

30 Girado Caballero, Op. Cit. pág. 156

31 Entrevista a Edgar Sarmiento, jefe de la División de Tierras del Cerrejón, Cerrejón Zona Norte, 29 de junio de 2006, casete No 02 .

32 Entrevista a Edgar Sarmiento, Ibíd.

33 Salas Bahamón, Jaime Ernesto, (2004). "El Cerrejón y sus efectos: una perspectiva socioeconómica y ambiental", , junio de 2004, disponible en: www.lablaa.org/blaavirtual/tesis/ colfuturo/elcerrejonysusefectos.pdf, pág. 10. Bogotá.

34 Fajardo Gómez, Remedios, (2007). "Violación sistemática de los derechos humanos", En: Chomsky, Aviva. Garry Leech y Steve Striffler. Bajo el manto del carbón. Pueblos y multinacionales en las minas de El Cerrejón, Colombia, Casa Editorial Pisando Callos, pág. 21. Bogotá.

35 Ibíd. págs. 21 y 22.

Palobrano. 9 Agosto/2008 
36 Ibíd, pág. 34.

37 Herrera Ángel, Marta. (2002), Op. Cit. pág. 83

38 Barrera Monroy, Eduardo. (2000), Op. Cit., pág. 74

39 Entrevista a Edgar Sarmiento, Cerrejón Zona Norte, junio de 2006, Casette $N^{\circ} 02$

${ }^{40}$ Yanama: concepto guajiro para referirse al trabajo comunitario. Para el siglo XVIII, la actividad de Yanama estaba estructurada sobre un principio de reciprocidad: El wayúu que trabajaba en la tarea de otro, se veía beneficiado luego con el trabajo de éste. Barrera Monroy, Eduardo. (2000). Op. Cit. pág. 91.

41 Ardila, Gerardo (Ed.), (1990). La Guajira: de la memoria al porvenir. Una visión antropológica, Universidad Nacional de Colombia, pág. 282. Bogotá.

42 Echeverri, Jonathan. Op. Cit. pág. 87

43 Solano Sardot, Ensito. (1990). "Carbogringocol", Antena informativa, junio - julio, pág. 21. Maicao.

44 Girado Caballero, Op. Cit., pág. 178

${ }^{45}$ Echeverri, Jonathan. Op. Cit, pág. 89.

46 "Testimonio de José Tulio Pérez desde la comunidad de Tabaco" (Contraportada), Chomsky. Leech. Striffler., Op. Cit. Pág. 223.

47 Ibíd. pág. 52 